\title{
Laser therapy in the treatment of peri-implantitis, new solutions to new problems
}

\author{
Vrushali Abhyankar* \\ Assistant Professor of Periodontology, UTHSC, College of Dentistry, USA
}

Dental implants have revolutionized dentistry in ways that were unimaginable in the last century. Partially and even completely edentulous patients can now hope to have fixed restorations which feel and function like natural teeth. Long term studies have shown implant therapy to be a very predictable option with success rates in the higher nineties. Osseointegration, the direct contact of vital bone to an implant surface is expected to be present throughout the functional life of the implant. But as it is said, every good thing must end, implant related associated biological complications have raised their ugly head and nearly $48 \%$ of implant cases have shown to have implant disease [1].

The American Academy of Periodontology defines Peri-implant mucositis as being characterized by visual signs of inflammation including bleeding on probing that may or may not be plaque induced, whereas as peri-implantitis as an inflammation associated with progressive bone loss. Peri implant mucositis is a reversible condition but peri-implantitis has a nonlinear and accelerating pattern of bone loss in the absence of treatment [2]. Due to the analogy established between gingivitis and peri implant mucositis and periodontitis and peri-implantitis; treatment has been directed towards removal of plaque from the implant as on the tooth and regenerating the lost attachment apparatus for both teeth and implants.

A plethora of treatment options have been recommended for treatment peri-implantitis including non-surgical methods of mechanical instrumentation, use of antibacterial agents, open flap debridement, detoxification of implant surfaces with various chemical agents, regenerative biologics, variety of bone grafts and guided bone regeneration techniques. However, there is no consensus on the most predictable and ideal treatment option as a complete resolution of inflammation and bone regeneration is not seen with any singular treatment option.

Laser is an acronym for light amplification by stimulated emission of radiation. With the insurgence of laser technology along with advances in dental implantology, there is a growing propensity for the use lasers in the treatment of peri-implant diseases. The collimated monochromatic light has the ability to produce various effects like coagulation, vaporization and warming of tissues and therefore has multitudinous applications in implant dentistry including non-surgical and surgical periodontal therapy and decontamination of diseased implants, depending on the energy levels of the laser. They also offer

Copyright: (C2018 Abhyankar V. This is an open-access article distributed under the terms of the Creative Commons Attribution License, which permits unrestricted use, distribution, and reproduction in any medium, provided the original author and source are credited. certain advantages over conventional surgical protocols including decreased pain, haemostasis, and decontamination of implant surface with bacteria, decreased anaesthesia, better wound healing and less scar tissue formation. Isolated cases have even shown bone regeneration and re-osseointegration after treatment with $\mathrm{CO} 2, \mathrm{Nd}$ :Yag or $\mathrm{Er}$ : YSGG lasers [3].

Diode lasers operating between $810-980 \mathrm{~nm}$ wavelength, Nd:YAG laser at $1064 \mathrm{~nm}$, Er:YAG at $2940 \mathrm{~nm}, \mathrm{Er}, \mathrm{Cr}: Y S G G$ at $2780 \mathrm{~nm}$ and $\mathrm{C} 02$ at 10,600 $\mathrm{nm}$ are the most popular lasers used in the treatment of peri-implantitis and multiple studies have reported their use in salvaging ailing implants [4]. However, it has not been possible to draw definite conclusions from them due to heterogeneity in types of lasers, their wavelengths, non-standardized cases, type of surgical or nonsurgical approach used, limited sample size and selection bias. The only consensus reached is that non-surgical approaches have limited efficacy in causing improvements in clinical parameters for periimplantitis [5].

Lasers, though a promising treatment modality do not have the unequivocal backing of large randomized control clinical studies to support their use as a singular treatment modality in treatment of periimplantitis. Er: YAG, diode and $\mathrm{CO} 2$ lasers have shown some evidence of reduction in probing depths, attachment gain and peri-implantitis reduction in short term studies. Future research is needed to emphasize the specific benefits obtained with specific lasers. Till then, it will have to endure with the skepticism reserved for novel treatment modalities.

\section{References}

1. Sequeira V, Todkar MM, Abhyankar V, Fernandes G (2018) Prevention of PeriImplantitis: A Narrative Review. J Dent Oral Care Med 4: 106

2. G Caton J, Armitage G, Berglundh T, Chapple ILC, Jepsen S, et al. (2018) A new classification scheme for periodontal and peri-implant diseases and conditions Introduction and key changes from the 1999 classification. J Clin Periodontol 45: S1S8. [Crossref]

3. Lin GH, Suarez Lopez Del Amo F, Wang HL (2018) Laser therapy for treatment of peri-implant mucositis and peri-implantitis: An American Academy of Periodontology best evidence review. J Periodontol 89: 766-782. [Crossref]

4. Romanos G (2015) Current concepts in the use of lasers in periodontal and implan dentistry. J Indian Soc Periodontol 19: 490-494. [Crossref]

5. Kotsakis GA, Konstantinidis I, Karoussis IK, Ma X, Chu H (2014) Systematic review and meta-analysis of the effect of various laser wavelengths in the treatment of periimplantitis. J Periodontol 85: 1203-1213. [Crossref]

*Correspondence to: Vrushali Abhyankar, MDS. MS Assistant Professor Periodontology, Diplomate, American Academy of Periodontology, UTHSC, College of Dentistry, 875, Union Avenue, Room C513, Memphis, TN-38163, USA, Tel: (901)-448-6271; Fax: (901)-448-1294; E-mail: vabhyank@uthsc.edu

Received: October 11, 2018; Accepted: October 22, 2018; Published: October 25, 2018 